East African Medical Journal Vol. 85 No. 2 February 2008

PICA PRACTICES OF PREGNANT WOMEN IN NAIROBI, KENYA.

P. O. Ngozi, PhD, Senior Lecturer, Department of Nursing Sciences, Faculty of Health Sciences and Technology, College of Medicine, University of Nigeria, Enugu Campus, Enugu, Nigeria

\title{
PICA PRACTICES OF PREGNANT WOMEN IN NAIROBI, KENYA
}

\author{
P. O. NGOZI
}

\begin{abstract}
Objectives: To establish the prevalence of pica behaviour during pregnancy; to identify the substances commonly ingested and their prevalence; and to determine the characteristics of women who reported practising pica.

Design: Descriptive, cross sectional study involving use of questionnaire administered in interview format.

Setting: Pumwani Maternity Hospital, Nairobi, Kenya.

Subjects: One hundred and seventy one antenatal women with a mean age of $28.1( \pm 7.3)$ years. Subjects were selected based on availability; accessibility and willingness to participate in the study.

Results: Seven hundred and ninety three $(\mathbf{7 4 . 0 \% )}$ participants reported practising pica regularly on daily basis. Pica prevalence categorised by substances ingested was as follows: soft stones (odowa); $89.8 \%$; soil, $61.2 \%$; and others, $9.6 \%$ and no pica, $26.0 \%$. Majority of women who reported practising pica $(62.5 \%)$ ingested more than one substance. Most women who practised pica reported having experienced strong cravings prior to ingestion of pica items, childhood pica, pica before pregnancy, pica in previous pregnancy and a history of pica in family members and significant others in the community.

Conclusions: Pica prevalence was significantly high among the subjects indicating that pica in pregnancy might be more common and independent in Kenya than health care providers assume or observe. There is need to routinely screen pregnant women for pica during antenatal visits as this will provide a more systematic and a less expensive way of establishing its epidemiological status. A nation-wide investigation of pica prevalence is also recommended in order to establish pica prevalence at national level and among different socio-economic groups. Further studies are also needed to establish possible health consequences of pica on mother and child.
\end{abstract}

\section{INTRODUCTION}

Many pregnant women have been observed to develop strong bizarre cravings, for and repeatedly ingest items that are not culturally accepted food substances during pregnancy. This phenomenon is referred to as pica (which is Latin word for magpie, a bird notorious for eating almost anything).

The term pica has been described as an eating disorder characterised by the persistent ingestion of non-nutritive substances for a period of at least one month at an age in "which this behaviour is developmentally inappropriate (1).

The patterns of ingestion are referred to as "phagias" (2) such as geophagia: eating soil, clay, sand or chalk; lithophagia: eating stone; pagophagia: eating ice or freezer frosts; plumbophagia: eating lead; amylophagia: eating laundry starch; coprophagia: eating faeces (2) and so on.

Evidence from studies carried out in different parts of the world has established pica practices during pregnancy to be a world-wide phenomenon (3-7) and the nature of substances ingested to vary in type and extent in different parts of the world. The more commonly reported ingested substances include clay, soil, sand, ice blocks, freezer frosts, laundry starch, and corn starch. Other reported pica substances include ashes, cigarette butts, stones, pebbles; soap, baking soda, baking powder, baby powder, raw potatoes, lead, burnt match heads, vinyl 
gloves, latex gloves, faeces, plastic, pencil erasers, hair, finger nails, pieces of papers, paint chips, plaster, coal, chalk, plastic bulbs, coffee grounds, charcoal, soot, needles, coins, screws, thumbtacks, glue, buttons, toothpaste and cloth (2-4). Going by the above lists, it seems that no substance is immune from the imagination of pregnant women with pica propensity.

Globally, the available literature shows that the prevalence rate of pica varies from place to place and has been reported to range from 0 to $68 \%$ depending on the characteristics of the population studied (4). In a study involving 553 urban pregnant, otherwise healthy African-American women, Edwards et al (5) reported that $8.1 \%$ of their respondents practiced pagophagia, no geophagia was reported. A similar low prevalence rate $(8.8 \%)$ involving geophagia and pagophagia was documented by al-Kanhal and Bani (8) in a study involving 321 pregnant Saudi Arabian women. Other investigators who reported low pica prevalence rates included Smulian et al (4) who documented 14.4\% prevalence in a sample of 125 women from rural obstetric population in Columbus, USA; and Walker et al (9) who recorded $2.2 \%$ and $1.6 \%$ prevalence rates respectively among the Indian and Caucasian pregnant women.

Some studies carried out in Western societies reported high prevalence rates in their subjects. Corbett et al (10), for example, recorded $38.0 \%$ prevalence in a study involving 128 antenatal women in Greenville, USA. They documented that AfricanAmerican women reported practising pica more often than other ethnic groups in their study. Also, about $8.6 \%$ of their respondents reported practising polyphagia, that is, ingestion of more than one substance. Similar rates were recorded by Simpson $e t$ al (6) whose study revealed a prevalence of $44 \%$ and $31 \%$ pica respectively in two groups of low-income women born in Mexico.

Highest pica prevalence rates involving mainly geophagia were reported in studies carried out in African countries. Walker et al (11) reported a 38.3\% and $44 \%$ pica prevalence rates respectively among the urban and rural South African pregnant women in their study. Tayie and Lartey (12) reported $48 \%$ geophagia with clay eating forming the major form of pica in a sample of Ghanaian pregnant women studied.InNigeria, Sule and Madugu (7)documented a $50 \%$ pica prevalence among the pregnant women studied in Zaria.

In Kenya, the only published works on pica prevalence in pregnancy have been those of Giessler etal $(13,14)$ which investigated geophagia in pregnant women attending antenatal clinic at Kilifi District Hospital in Coast Province, Kenya at different times. In one of the studies (13) involving 275 pregnant women, $56 \%$ reported eating soil regularly and in the later study (14) involving 52 pregnant women, $73 \%$ reported practising geophagia on regularbasis. These studies specifically investigated geophagia and found it to be a common practice among the study population. In the twostudies $(13,14)$ theinvestigators however did not attempt to identify other substances ingested by pregnant women in this society.

Lithophagia is another form of pica that is reportedly being practised by both pregnant and non pregnant women in Kenya. This involves eating 'odowa', a light yellow soft stone reportedly dug out from excavation sites at Kajulu hills in KisumuDistrict and cut out into chips (odowa chips) for consumption. Ajanja (15) in a newspaper documentary reported that "odowa" eating has spread to major towns in Kenya and beyond and that the stones are sold at the roadsides, in the markets and shopping malls. According to the local people their is a believe that the soft stones increase the woman's strength during labour hence pregnant women take them as iron supplement and as a tonic. The practice of "odowa" eating in Kenya has however not been investigated empirically.

The present study has been inspired by the apparent scarcity of empirical studies on pica prevalence during pregnancy in the country. It is hoped that the present study will supply the baseline data.

\section{MATERIALS AND METHODS}

This was a descriptive, crosssectional study conducted at Pumwani Maternity Hospital (PMH) Nairobi, Kenya, between September 2004 and February 2005. A signed approval for the study was obtained from the Pumwani Maternity Hospital Research and Ethics Committee. PMH has a capacity of 350 beds and 100 cots. The average number of antenatal mothers from Monday to Friday is about 60 per day.

The study used a convenience sample of 1071 low income pregnant women who were recruited during their antenatal visit. Selection of subjects was based on availability, accessibility, willingness to participate, and absence of obvious physical and emotional distress. Women experiencing pains or bleeding or in early stage of labour or in any other physical or emotional discomfort were excluded from the study. The purpose of the study was explained to available pregnant women who attended antenatal clinic from Monday to Friday every week during the 
eight weeks data collection period. The volunteers who gave a verbal consent or signed a consent statement to participate in thestudy were interviewed consecutively until the desired sample size was reached. Subjects were interviewed before or after they had been attended to by the nursing or medical staff .

Convenience sampling method was adopted for the study because pica prevalence was not known since it had not been explored in Kenya and so could not be estimated. Thus, the present study is considered a very preliminary one in the area of pica prevalence in Kenya. In addition, the nature of the population studied was another determinant factor in the choice of the sampling method adopted for the study. The population was constituted of pregnant women who made antenatal visits once in several weeks or even in months and whose stay in the clinic lasts only a couple of hours. This made it difficult to keep accurate track of them. It therefore makes more sense to interview the available volunteers as they come and go.

The instrument for data collection was a questionnaire designed and validated by the investigator through pilot testing involving ten pregnant mothers at Kenyatta National Hospital (KNH), Nairobi. The questionnaire contained twenty questions, which were mainly open ended with few closed ended items designed to address the objectives set for the study. The questionnaire was administered in an interview format to all eligible participants who voluntarily consented to be involved in the study after the purpose of the study was explained to them.

\section{RESULTS}

Data were collected from 1071 pregnant women during the eight weeks period of data collection. All data were collected at nominal level and were either listed or categorised in groups and results presented in frequencies and percentages.

Socio-demographic profile: The majority 860 (80.3\%) of respondents were within the age range of 20-39 years and with a mean age of $28.1( \pm 7.3)$ years. More than half $665(62.1 \%)$ were married and a similar proportion 674(62.9\%) were multiparous. One hundred and thirty nine $(13.0 \%)$ were teenagers and some were multiparous. About 624 (58.3\%) constituted of those respondents who either attempted various levels of primary education without completion 250 (23.3\%); and those who completed primary education 374 (34.9\%). About 215(20.19\%) dropped out of secondary school and $96(9.0 \%)$ completed secondary education. Sixty nine (6.4\%) had no formal education; $65(6.1 \%)$ had college education and only two $(0.2 \%)$ had university education. About one fifth, 229 (21.4\%) of the respondents were not working and were either housewives or students; $337(35.2 \%)$ were engaged in petty trading; while 231 (21.6\%) were peasant farmers; and the rest, $234(21.8 \%)$ were mostly engaged in different categories of low paid jobs (Table 1).

\section{Table 1}

Socio-demographic characteristics of respondents $(n=1071)$

Characteristic Frequency $(\%)$

Age (years)

$15-19$ $139 \quad 13.0$

$20-29$

$614 \quad 57.3$

$30-39$

$246 \quad 23.0$

$40-49$

$\begin{array}{ll}72 & 6.7\end{array}$

Marital Status

Single (never been married)

$\begin{array}{ll}352 & 32.9\end{array}$

Married

Separated/Divorced (widowed)

$54 \quad 5.0$

Parity

Primiparous

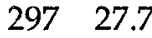

Multiparous

$774 \quad 72.3$

Highest Educational Level

No formal education

$69 \quad 6.4$

Attempted primary education

$250 \quad 23.3$

Completed primary education

$374 \quad 34.9$

Attempted secondary education 21520.1

Completed secondary education $96 \quad 9.0$

College

$65 \quad 6.1$

University

20.2

Occupation

Not working (e.g. house wife, student, etc)

$229 \quad 21.4$

Petty trading

$377 \quad 35.2$

Farming (peasant farmers)

$231 \quad 22.6$

Hair dressing

$89 \quad 8.3$

Clerical officers

$47 \quad 4.4$

Teaching

$38 \quad 3.5$

Others*

$60 \quad 5.6$

${ }^{*}$ Others included shop attendants $17(1.6 \%)$; hospital attendants $14(1.3 \%)$; hotel/bar attendants $9(0.8 \%)$; office attendants $9(0.8 \%)$; babysitting/ house helps $6(0.6 \%)$; community midwives $3(0.3 \%)$; and police constables $2(0.2 \%)$. 
Prevalence of pica: Results on pica prevalence show that a total of $793(74.0 \%)$ participants reported practicing pica regularly during pregnancy. About one third of this number, $266(24.8 \%)$ reported practicing pica without experiencing any form of cravings while $527(49.2 \%)$ reported experiencing strong cravings together with pica. Sixty one (5.7\%) participants reported experiencing cravings regularly but without ingesting the craved substances, while $217(20.3 \%)$ denied any experience of cravings or pica during pregnancy (Table 2 ).

\section{Table 2}

Prevalence of pica during pregnancy as reported by respondents $(n=1071)$

\begin{tabular}{lcc}
\hline Incidence of pica & Frequency & $(\%)$ \\
\hline Absence of cravings with pica & 266 & 24.8 \\
Cravings with pica & 527 & 49.2 \\
Cravings without pica & 61 & 5.7 \\
Absence of cravings without pica & 217 & 20.3 \\
\hline
\end{tabular}

Substances ingested: Pica prevalence categorised by substances ingested as reported by respondents was as follows: soft stones (odowa) (89.8\%); soil (red soil, anthill soil, dried mud/ clay) (61.23\%); charcoal and ash (burnt sugar cane wastes) $(6.9 \%)$; ice blocks $(0.8 \%)$; pieces of paper $(0.6 \%)$; soap powder $(0.5 \%)$, inhaling the odour emanating from human excreta $(0.5 \%)$; and inhaling the odour from husbands' dirty work clothes $(0.3 \%)$ (Table 3$)$. More than half of the women who practiced pica, $496(62.5 \%)$ reported ingesting more than one substance (polyphagia) either together at a time or interchangeably.

\section{Table 3}

Substances ingested reported by respondents $\left({ }^{*} n=793\right)$

\begin{tabular}{|c|c|c|}
\hline Substance & Frequency & $(\%)$ \\
\hline Soft stones (odowa) & 712 & 89.8 \\
\hline $\begin{array}{l}\text { Soil (red soil, anthill soil, } \\
\text { dried mud/clay) }\end{array}$ & 485 & 61.2 \\
\hline Charcoal & 40 & 5.0 \\
\hline Ash (burnt sugar cane wastes) & 15 & 1.9 \\
\hline Ice blocks & 6 & 0.8 \\
\hline Paper (pieces of paper) & 5 & 0.6 \\
\hline Soap powder (detergent) & 4 & 0.5 \\
\hline Faeces (inhaling the odour) & 4 & 0.5 \\
\hline Dirty clothes (inhaling the odour) & 2 & 0.3 \\
\hline
\end{tabular}

Rate of ingestion: Majority of women 643 (81.1\%) reported ingesting the substances between two and three times with average ingestion rate of 2.4 times daily (Table 4).

Table 4

Frequency of ingesting pica substances reported by respondents $(n=793)$

\begin{tabular}{lcc}
\hline Number of times per day & Frequency & $(\%)$ \\
\hline Once a day & 89 & 11.2 \\
$2-3$ times & 643 & 81.1 \\
$>3$ times & 61 & 7.7 \\
\hline
\end{tabular}

Sources of pica substances: A major source of procurement of pica substances was through purchase $(98.6 \%$ ) from roadsides, markets, shopping malls and kiosks. Other sources included immediate environment such as ground $(30.1 \%)$, termiteria or anthill nests (23.2\%), walls of mud houses (22.8\%), and others such as refrigerators, deep freezers, and so on $(6.1 \%)$ (Table 5).

Table 5

Source of pica substances reported by respondents $\left({ }^{*} n=793\right)$

\begin{tabular}{lcc}
\hline Source & Frequency & $(\%)$ \\
\hline Purchase (from shops, & & \\
markets, roadsides, etc) & 782 & 98.6 \\
Ground (for red soil) & 239 & 30.1 \\
Temiteria (anthill nests) & 184 & 23.2 \\
Walls of mud houses & 181 & 22.8 \\
Others & 48 & 61 \\
\hline
\end{tabular}

*Categories not exclusive.

Characteristics of women who reported practicing pica: Majority of women who practiced pica also reported experiencing cravings or compulsion to ingest pica substances, 527 (66.5\%); childhood pica, 348 (43.9\%); pica before pregnancy, $400(50.4 \%)$; pica in previous pregnancy 425 (56.3\%); pica in family members 616 (77.7\%); and pica in other members of the community (such as friends and neighbours) $386(48.7 \%)$. 


\section{Table 6}

Characteristics of women who reported practising pica $\left({ }^{*} n=793\right)$

\begin{tabular}{lcc}
\hline Characteristic & Frequency & $(\%)$ \\
\hline Cravings & 527 & 66.5 \\
Childhood pica & 348 & 43.9 \\
Pica before pregnancy & 400 & 50.4 \\
Pica in previous pregnancy & 425 & 56.3 \\
Pica in family members & 616 & 77.7 \\
Pica in friends/neighbours etc 386 & 48.7 \\
\hline
\end{tabular}

${ }^{\star}$ Categories not exclusive

\section{DISCUSSION}

The present study was conducted primarily to investigate the prevalence of pica behaviour during pregnancy and to identify the substances commonly ingested and their prevalence and sources. Further, the study explored the characteristics of women practicing pica, which may have influenced their behaviour.

Majority of the respondents $(70.3 \%$ ) were below the age of 30 years, and most of them were married and multiparous. This finding is not surprising because in African traditional society, it is a common practice for female children who are educationally disadvantaged to marry and have children earlier than those women who have opportunity to go to school and pursue higher education.

The respondents were also mostly of low socio economic status (Table 1). These findings were not surprising because the Pumwani Maternity Hospital was established to provide integrated maternity services to the low income members of the society at affordable costs. Besides, the Pumwani estate where the maternity hospital is situated is mainly inhabited by low income people.

As regards pica prevalence, the present study has established both the presence as well as a high prevalence of pica behaviour in the pregnant women studied. More than two thirds $(74.0 \%)$ of the respondents reported practicing pica regularly on daily basis. These findings corroborate the findings of other studies carried out in Kenya (13-15) and other parts of Africa $(7,11,12)$ and Western societies $(3,6)$ which reported both the existence as well as high prevalence of pica during pregnancy among their respective study subjects.

The results on pica prevalence is however inconsistent with what was documented by Smulian et al (4) that the prevalence of pica during pregnancy range between 0 and $68 \%$ depending on the characteristics of the population studied. The findings from the present study revealed a higher prevalence rate $(74.0 \%)$ and are suggestive that pica prevalence is neither static nor declining but increasing.

Further breakdown of the findings show that notall respondents who reported experiencing cravings ingested the craved substance(s). About 61 (5.7\%) women admitted experiencing thestrong urge toingest one substance or the other occasionally or regularly as the case may be but were able to restrain themselves fromingesting the craved items through various means. Twenty five $(41.0 \%)$ women said that they controlled the urge by purposely determining not to ingest the craved items, 21 ( $34.4 \%$ ) said they controlled by eating biscuits or similar items, and $15(24.6 \%)$ claimed to achieve control by lying down quietly and refusing to get up until the urge subsided. This finding is encouraging as it is suggestive that one can still control the urge irrespective of how strong it may be. It shows that women who practiced pica could be assisted through effective intervention measures to overcome this behaviour. This finding is in congruence with certain tenets of Rogerian client-centred theory of human behaviour which see human organism as capable of self-direction and self-regulation if he is assisted to develop insight into (his) problems or circumstances. The findings also reveal that a substantial number, 266 (24.8\%) of respondents who practised pica denied experiencing any form of craving or urge at any point in time prior to their ingestion of pica items. It is possible that this group of respondents practised pica out of personal habit, cultural beliefs, or what they believe to benefit from the ingested substances.

The finding is perhaps suggestive that these women lack adequate information as regards their nutritional and health needs and how to meet them during pregnancy. This group of respondents may no doubt benefit from health education and counselling.

Substances reported to beingested as presented on Table 3 are consistent with most of the commonly reported pica items in literature (2-4) except soft stones that was mentioned as one of the less frequently ingested items. This result shows that pica substances have not changed but may be increasing in number.

The results show that eating soft stones or lithophagia $(89.9 \%)$ is more commonly practised and thus constitutes a major form of pica practised by pregnant women involved in this study. This finding differed from the results reported from studies carried out in Kenya $(13,14)$ and other parts of Africa $(2,7,11,12)$, which reported that soil eating (geophagia) was the most common form of pica practised during pregnancy in these societies. 
The findings on the other hand confirms Ajanja's (15) assertions in his documentary that 'odowa' eating has so much spread in the past few years among both pregnant and non pregnant women that it has established itself as a consumer product in major cities in Kenya and beyond. The high prevalence of 'odowa' eating (89.9\%) among the respondents has substantiated these assertions.

The results also did not confirm the results of studies conducted in Western societies $(3,5)$, which reported that pagophagia (eating ice and freezer frosts) was the most common form of pica among the population of pregnant women studied. In present study, only six women $(0.8 \%)$ reported ingesting ice blocks. The prevalence of ice eating may be low because the study population constituted mostly of women of low income group who may not afford refrigerators or deep freezers.

Interestingly four women $(0.5 \%)$ reported enjoying inhaling odour from faeces (human excreta) and two other women $(0.3 \%)$ reported inhaling odour from husband's dirty work clothes. These findings may be a case of olfactory craving of pregnancy described by Cooksey (16) as theingesting more than one substance involving particularly soft stones and soil either together or alternatively on regular basis. When probed further, the reasons given by respondents for ingesting more than one substance included physical availabilityingesting more than one substance involving particularly soft stones and soil either together or alternatively on regular basis. When probed further, the reasons given by respondents for ingesting more than one substance included physical availability of the substance at the time of need and availability in terms of monetary cost, cultural beliefs, and perceived benefit or effect derived from the substance after ingestion. Many women explained that even though they preferred soft stones to soil because they are more hygienically prepared and safer and also have more micronutrients ("something") that make baby and mother stronger during labour, soil is more readily available and cheaper to procure, and at times, it is obtained free without any monetary cost. They also explained that soil particularly those obtained from walls of mud houses or temiteria when sprinkled with water or when rain drizzles on it emits a characteristic or peculiar aromatic odour which gives a palatable texture or taste in the mouth when ingested. Based on the foregoing reasons, majority of respondents ingest soft stones alongside soil. This finding is in line with Corbett et al (10) study which reported that eleven women one out of the 49 who practiced pica were polyphagous, although the prevalence of polyphagia reported in their study was low, their sample size of 128 was also smaller than the sample used in this study.

Part of the results also shows that the rate of ingesting the pica substances was high (Table 4). The majority reported ingesting the substances between two and three times daily. The mean ingestion rate for the sample was 2.4 times per day. Although the quantity of the substances ingested at a time or per day was not determined in this study, this result calls for concern since ingesting any of the identified substances at that rate on regular basis could lead to serious health problems and complications. Literature on pica has, for example, shown that complications, such as helminthic infestations, iron deficiency anaemia and intestinal obstruction may occur from pica involving soil and soft stones (13,17-19), mercury poisoning from paper pica (18) and soon. The reasons for the high rate of ingestion may be due to cultural beliefs and practices, poverty, perceived benefits and other external influences such as advertising and promoting the "benefits" of soft stones by the market interest driven dealers. It may also be possible that these substances were eaten at this rate out of habit to satisfy their cravings which some of the respondents described as "too compelling and powerful to resist".

The findings on the sources of pica substances reported by the respondents (Table 5) show that the pica materials are readily available and accessible in the respondents' environment. It is possible that the high accessibility to pica substances has positive influence on the prevalence and persistence of pica behaviour among the respondents. This is saying that if the substances are not readily available or are difficult to procure, one would expect a decline in pica behaviour.

On the pica practitioners characteristics, the findings reveal that majority of women who practiced pica reported experiencing one or combinations of the following: persistent urge to ingest pica substances (cravings), childhood pica, pica before pregnancy, pica during previous pregnancy, and presence of pica in family members, and other significant persons such as friends or neighbours who practiced pica during pregnancy or in non pregnant state. It appears these factors exert multiple influences on pica behaviour. For women experiencing persistent craving, the urge may be too overpowering for most women to control or resist thus leading to repeated ingestion's. with greater risk to health. It is likely that women with a history of childhood pica, pica before pregnancy and pica in previous pregnancy have developed habitual tendency from past experience towards 
pica. Psychological literature particularly psychoanalytic theories, on human behaviours are replete with theoretical postulations that early or childhood experiences tend to persist to influence later behaviour. There is also a possibility that significant others such as family members, friends and neighbours have great influence on human behaviours. This is likely to be due to family, peers and community shared habits and tendencies. This study supports the findings from other studies on characteristics of women with pica behaviour $(4,6$, 7 ). The findings also substantiate the observations made by other researchers that pica is most commonly practiced among people from low socioeconomic backgrounds and who live in rural communities $(5,6,11)$. Majority of respondents in the present study were of low socio economic status as can be seen from their socio-demographic profiles (Table 1).

Although Pumwani Maternity Hospital is situated in Nairobi, the capital of Kenya, the Pumwani estate could be described as an urban slum because it is mostly inhabited by low-income group of the population.

In conclussion the present study has established that pica exists and at a high prevalence rate among the study subjects. The most common forms of pica were lithophagia and geophagia, which may occur singly or together in one person. Pica behaviour was highly influenced by both intrinsic (personal) and external factors. The high pica prevalence in this study is indicative that pica behaviour might be more common and widespread in this society than healthcare providers realise.

The implication of the findings of this study is that if this practice is not stopped or controlled the trend will continue with subsequent generations as a result of reinforcement, modelling and learning.

This study is not without limitation. It was conducted on low income pregnant women at PMH so the findings are limited to that population. Nonetheless, the study has provided baseline data for further research on pica practices and related issues among pregnant women in Kenya. There is need for nation-wide cross socio-cultural study on pica prevalence involving pregnant women from different socio-economic background in order to establish pica prevalence at national level and among different socio-economicgroups. Such further studies may discover other pica substances this study did not identify. There is also need for further studies to establish possible health consequences on mother and child associated with (specific) pica practices during pregnancy. Finally, there is also need to routinely screen pregnant women for pica during antenatal visits. This will provide a more systematic and a less expensive way of establishing its epidemiology status among pregnant women in Kenya.

\section{ACKNOWLEDGEMENTS}

To the Pumwani Maternity Hospital Research and Ethics Committee without whose approval thisstudy would have been impossible. My appreciation is also extended to the authorities of Pumwani Maternity Hospital, particularly Dr. Charles Wanyonyi, the Medical Director and Ms Millicent Ambesa, the Matronin-charge for their co-operation and necessary help during data collection period. My sincere appreciation also goes to Emily Chesumei, Jane Ngivu, Julian Maithya and Fellisters Mutisya, the nurse interns who collected the data for the study

\section{REFERENCES}

1 American Psychiatric Association, Diagnostic and Statistical Manual of Mental Disorders: DSM - IVC (4th edition). Washington DC; American Psychiatric Press, 1994.

2 Rose, E. A., Porcelli, J. H., and Neale, A.V. Pica: Common but commonly missed. J. Am. Board Fam. Pract. 2000; 13: 352-358.

3 Rainville, A. J., Pica practices of pregnant women are associated with lower maternal haemoglobin level at delivery. J. Am. Diet. Assoc. 1998; 98: 293 - 296.

4 Smulian, J. C., Motiwala, S. and Sigma, R. K. Pica in a rural obstetric population. South Med J. 1995; 88: 1236-1240.

5 Edwards, C. H., Johnson, A. A., Knight, E. M. et al. Pica in an urban environment. J. Nutr. 1994; 124: 9545-9625.

6 Simpson, E., Mull, M. D., Longley, E. and East, J. Pica during pregnancy in low-income women born in Mexico. West J. Med. 2000; 173: 20-25.

7 Sule, S. and Madugu, H. N. Pica in pregnant women in Zaria, Nigeria. Niger J. Med. 2001; 10: 25-27.

8 al-Kanhal, M. A, and Bani, I. A. Food habits during pregnancy among Saudi women. Int. J. Vitam. Nutr. Reg. 1995; 65:206-210.

9 Walker, A. R. P., Walker, B. F. Sokaria, F. I., and Cannan, R. J. Pica. J. Roy Health. 1997;117:280-284.

10 Corbett, R. W., Ryan, C. and Weinrich, S. P. Pica in pregnancy: does it affect pregnancy outcomes? MCN Am. J. Matern. Child Nurse. 2003; 28: 183-189.

11 Walker, A. R., Walker, B.F., Jones, J., et al. Nausea and vomiting and dietary cravings and aversions during pregnancy in South African women. Br. J. Obstet. Gynaecol. 1985; 92:484-489.

12 Tayie, F. A. K. and Lartey, A. Pica practice among pregnant Ghanaians: Relationship with infant birthweight and maternal haemoglobin level. Ghana Med. J. 1999; 33 :67 -76. 
13 Giessler, P. W., Shulman, C. E. Prince, R. J., et al. Geophagy, iron status.and anaemia among pregnant women on the coast of Kenya. Trans. $R$. Soc. Trop. Med. Hyg. 1998; 92:549-553.

14 Giessler, P. W., Prince R. J., Levene, M., et al. Perceptions of soil-eating and anaemia among pregnant, women on the Kenyan Coast. Soc. Sci. Med. 1999; 48: 1069-1079.

15 Khayesi Ajanga, "Village markets stones as 'odowa' eating catches on". The Standard. Tuesday, January 4, 2005, P.8.
16 Cooksey, N. R. Pica and olfactory craving of pregnancy: how deep are the secrets? Birth. 1995;22: 129-137.

17 Horner, R. D., Lackey, C. J., Kolasa, K. and Warren, K. Pica practices of pregnant women. J. Am. Diet. Assoc. 1991; 91:34-38.

18 Menge, H., Lang. A. and Cuntze, H. Pica in Germany amylophagia as the aetiology of iron deficiency anaemia. Z. Gastroenterol. 1998; 36: 635-640.

19 Federman, D. G., Kirsner, R. S., and Federman, G. S. Pica: are you hungry for fact? Conn Med. 1997; 61: 207-209. 